\title{
Case Report \\ PUVA Induced Bullous Pemphigoid in a Patient with Mycosis Fungoides
}

\author{
Birgül Özkesici, ${ }^{1}$ Saliha Koç, ${ }^{2}$ Ayşe Akman-Karakaş, ${ }^{3}$ Ertan Yılmaz, \\ İbrahim Cumhur Başsorgun, ${ }^{4}$ and Soner Uzun ${ }^{3}$ \\ ${ }^{1}$ Clinic of Dermatology, Adıyaman University Training and Research Hospital, Adiyaman, Turkey \\ ${ }^{2}$ Clinic of Dermatology, Kepez State Hospital, Antalya, Turkey \\ ${ }^{3}$ Department of Dermatology and Venereology, Akdeniz University School of Medicine, Antalya, Turkey \\ ${ }^{4}$ Department of Pathology, Akdeniz University School of Medicine, Antalya, Turkey \\ Correspondence should be addressed to Birgül Özkesici; birgulozkesici@gmail.com
}

Received 13 November 2016; Accepted 27 March 2017; Published 16 April 2017

Academic Editor: Thomas Berger

Copyright (C) 2017 Birgül Özkesici et al. This is an open access article distributed under the Creative Commons Attribution License, which permits unrestricted use, distribution, and reproduction in any medium, provided the original work is properly cited.

\begin{abstract}
Background. Bullous pemphigoid is an autoimmune subepidermal blistering skin disease in which autoantibodies are directed against components of the basement membrane. The disease primarily affects the elderly people and in most of the patients inducing factors cannot be identified. Herein, we report a case of BP that occurred in a patient who was receiving PUVA therapy for the treatment of mycosis fungoides. Main Observation. A 26-year-old woman with mycosis fungoides developed blisters while receiving PUVA therapy. On physical examination tense bullae on the normal skin, remnants of blisters, and erosions were observed on her breasts, the chest wall, and the upper abdomen. Histopathological investigations revealed subepidermal blisters with eosinophilic infiltration and in direct immunofluorescence examination linear deposition of IgG along the basement membrane zone was observed. The diagnosis of bullous pemphigoid was also confirmed by ELISA and BIOCHIP mosaic-based indirect immunofluorescence test. Conclusions. PUVA therapy is an extremely rare physical factor capable of inducing bullous pemphigoid. So the development of blistering lesions during PUVA therapy may be suggestive sign of a bullous disease such as bullous pemphigoid and it should be excluded with proper clinical and laboratory approaches immediately after withdrawal of PUVA therapy.
\end{abstract}

\section{Introduction}

Bullous pemphigoid (BP) is an autoimmune subepidermal blistering skin disease, characterized by autoantibodies against structural proteins of the dermal-epidermal junction and clinically presented with cutaneous and/or mucosal blisters or erosions. It usually affects the elderly people. In the most cases, BP occurs sporadically without any obvious precipitation factors. However, the limited BP cases have been reported that are precipitated by UV radiation, medications, vaccination, radiation therapy, thermal burn, amputation stump, incisional hernia scar, and injection $[1,2]$. Herein, we report a case of BP that occurred in a patient who was receiving PUVA therapy for the treatment of mycosis fungoides.

\section{Case Report}

A 26-year-old woman with mycosis fungoides developed blisters while receiving 8-methoxypsoralen and ultraviolet A (PUVA) therapy, at session 17 when the dose of UVA was $7.01 \mathrm{~J} / \mathrm{cm}^{2}$ (cumulative dose was $70.66 \mathrm{~J} / \mathrm{cm}^{2}$ ) (Figure 1). The patient had no history of any other drug use. On physical examination tense bullae on the normal skin, remnants of blisters, and erosions were observed on her breasts, the chest wall, and the upper abdomen. The patch lesions of mycosis fungoides were also present on buttocks and lower abdomen of the patient (stage 1A). PUVA therapy had been stopped and skin biopsies have been taken from a newly formed blister for histopathology and perilesional uninvolved skin for direct immunofluorescence (IF) examination for 
TABLE 1: Cases of BP due to PUVA therapy.

\begin{tabular}{lcccc}
\hline Cases & Sex & Age (year-old) & $\begin{array}{c}\text { Why the treatment } \\
\text { of PUVA was given }\end{array}$ & Type of UVA \\
\hline $1(2)$ & Female & 45 & Vitiligo & Topical PUVASOL \\
$2(3)$ & Male & 50 & Psoriasis & Oral PUVA (methoxsalen) \\
$3(4)$ & Male & 80 & Psoriasis & Oral PUVA (5-MOP) \\
$4(5)$ & Female & 57 & Mycosis fungoides & Oral PUVA (8-MOP) \\
$5(6)$ & Female & 65 & Psoriasis & Oral PUVA (8-MOP) \\
$6(7)$ & Female & 67 & Psoriasis & UVA \\
$7(8)$ & Male & 58 & Psoriasis & PUVA (unspecified) \\
$8(9)$ & Male & 61 & Psoriasis & Oral PUVA (oxsoralen) \\
$9($ present case) & Female & 26 & Mycosis fungoides & Oral PUVA (8-MOP) \\
\hline
\end{tabular}

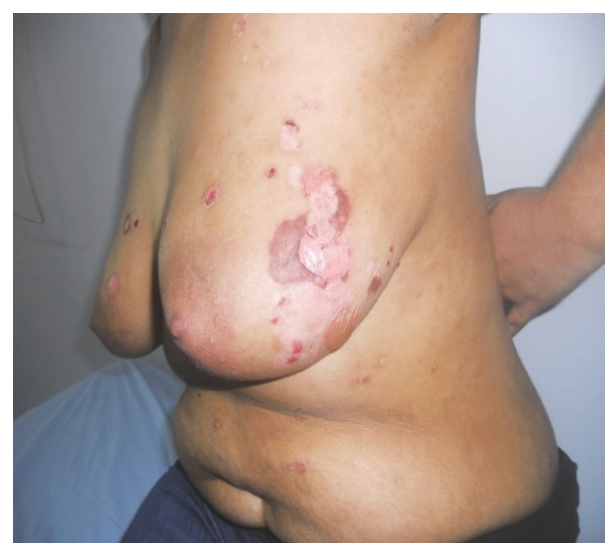

FIGURE 1: Clinical presentation of the patient; blisters, erosions, and remnants of blisters on her breasts and abdomen.

diagnosis. Histopathological examination showed subepidermal blisters with eosinophilic infiltration (Figure 2(a)) and in direct IF examination linear deposition of IgG along the basement membrane zone was observed. ELISA was positive for anti-BP180 antibody $(47 \mathrm{U} / \mathrm{mL})$. Also, BIOCHIP mosaicbased indirect IF test demonstrated a linear deposition of IgG along the basement membrane zone on the primate monkey esophagus, epidermal deposition on the salt-split skin substrate (Figure 2(b)), and anti-BP180 and anti-BP230 positivity on transfected EU90 cells.

Topical $0,05 \%$ clobetasol propionate cream treatment with a dose of $25 \mathrm{gr} /$ day was started after cessation of the PUVA therapy. Disease was gotten under control after 1 week and complete remission was achieved at 3rd week (Figure 3). Then the dose of clobetasol propionate was tapered monthly as $25 \mathrm{mg}$ on alternate days, twice a week, and once a week till it was discontinued after 4 months. Recurrence was not observed during follow-up period for 3 years. After 3 months of the treatment of BP, although patient had narrow band UVB therapy (25 sessions at the cumulative dose of 25.75 joule $/ \mathrm{cm}^{2}$ ) for her primary disease, mycosis fungoides, any recurrence of $\mathrm{BP}$ was not observed.

\section{Discussion}

The pathogenesis of BP is characterized by tissue-bound and circulating IgG autoantibodies against two components of the hemidesmosome, BP230 and BP180 [1]. The typical clinical presentation is tense blisters frequently concomitant with urticarial plaques. Most cases of BP occur sporadically without any obvious precipitation factors. Local irritation and damage to the skin have all been implicated in the induction of BP. There are limited numbers of reports suggesting that psoralen plus UVA (PUVA) therapy may trigger the development of BP (Table 1) [3-9]. In the majority of these patients PUVA was administered to treat psoriasis. But BP has also been reported previously in a patient with mycosis fungoides [5]. The role of PUVA in the pathogenesis of BP is poorly understood; however, there are some hypotheses that have been proposed. Danno et al. have demonstrated the alterations of keratinocyte surface and basement membrane markers by PUVA therapy [10]. So such changes may induce the production of $\mathrm{BP}$ autoantibodies by polyclonal activation of B cells [1]. On the other hand, PUVA may also alter the immunologic reactivity of T-helper and T-suppressor cells that may result in the development of the autoantibodies against native proteins [6]. Inversely, the protective effect of UVB irradiation has been showed by reducing the expression of pemphigoid antigens in organ-cultured normal human skin in a study [11]. In fact, after healing her PUVA induced $\mathrm{BP}$, our patient was treated by UVB for her mycosis fungoides without recurrence of BP.

Although it is difficult to generalize about the prognosis of PUVA induced BP because of the limited numbers of cases [5], it seems that its prognosis is better with mild and transient behavior than idiopathic ones [6].

\section{Conclusion}

Our case indicates that the development of blistering lesions during PUVA therapy may be suggestive sign of a bullous disease such as BP and it should be excluded with proper clinical and laboratory approaches immediately after withdrawal of PUVA therapy. 


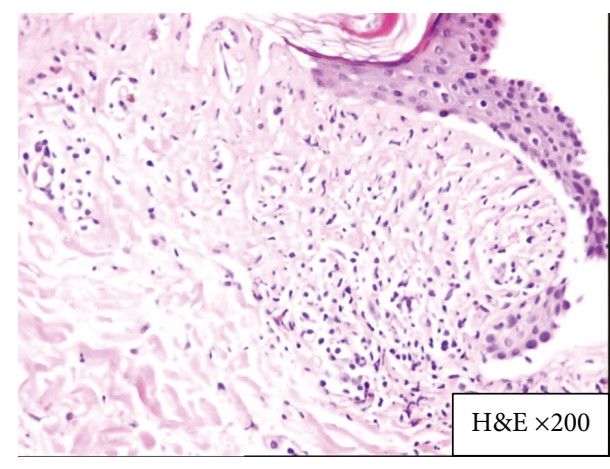

(a)

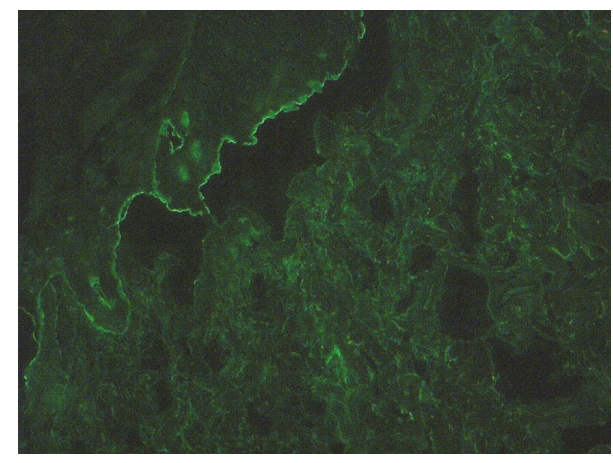

(b)

FIgURE 2: (a) Subepidermal blisters with eosinophilic infiltration $(H \& E \times 200)$. (b) BIOCHIP demonstrated epidermal deposition on the salt-split skin substrate.

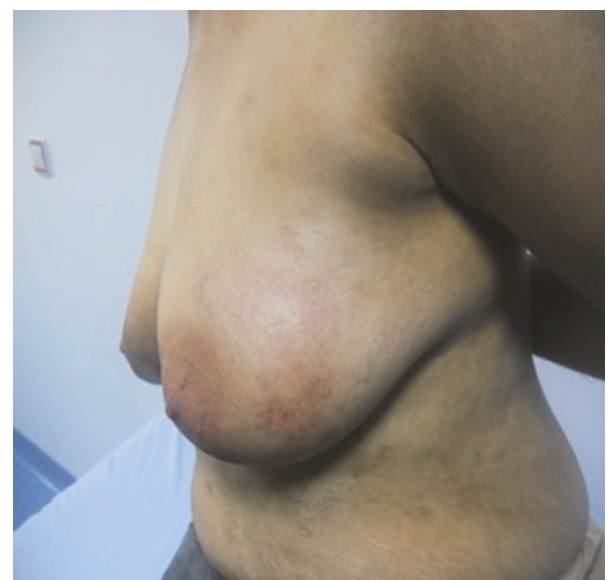

FIGURE 3: After treatment with $0,05 \%$ clobetasol propionate cream. Note the complete healing.

\section{Disclosure}

This has been presented at the 22nd EADV Congress, İstanbul-TURKEY, 2-6 October 2013.

\section{Conflicts of Interest}

The authors declare that they have no conflicts of interest.

\section{References}

[1] A. Lo Schiavo, E. Ruocco, G. Brancaccio, S. Caccavale, V. Ruocco, and R. Wolf, "Bullous pemphigoid: etiology, pathogenesis, and inducing factors: Facts and controversies," Clinics in Dermatology, vol. 31, no. 4, pp. 391-399, 2013.

[2] N. Riyaz, N. Nasir, V. Bindu, and S. Sasidharanpillai, "Bullous pemphigoid induced by topical PUVASOL," Indian Journal of Dermatology, Venereology and Leprology, vol. 80, no. 4, pp. 363364, 2014.

[3] E. A. Abel and A. Bennett, "Bullous pemphigoid: occurrence in psoriasis treated with psoralens plus long-wave ultraviolet radiation," Archives of Dermatology, vol. 115, no. 8, pp. 988-989, 1979.
[4] S. Perl, K. Rappersberger, D. Födinger, B. Anegg, H. Hönigsmann, and B. Ortel, "Bullous pemphigoid induced by PUVA therapy," Dermatology, vol. 193, no. 3, pp. 245-247, 1996.

[5] J. W. Patterson, M. Ali, J. C. Murray, and T. A. Hazra, "Bullous pemphigoid: occurrence in a patient with mycosis fungoides receiving puva and topical nitrogen mustard therapy," International Journal of Dermatology, vol. 24, no. 3, pp. 173-176, 1985.

[6] M. A. Barnadas, M. Gilaberte, R. Pujol, M. Agustí, C. Gelpí, and A. Alomar, "Bullous pemphigoid in a patient with psoriasis during the course of PUVA therapy: study by ELISA test," International Journal of Dermatology, vol. 45, no. 9, pp. 10891092, 2006.

[7] H. Washio, H. Hara, H. Suzuki, M. Yoshida, and T. Hashimoto, "Bullous pemphigoid on psoriasis lesions after UVA radiation," Acta Dermato-Venereologica, vol. 85, no. 6, pp. 561-563, 2005.

[8] N. Caca-Biljanovska, I. Arsovska-Bezhoska, and M. V'lckovaLaskoska, "PUVA-induced bullous pemphigoid in psoriasis," Acta Dermatovenerologica Croatica, vol. 24, no. 3, pp. 214-217, 2016.

[9] P. M. George, "Bullous pemphigoid possibly induced by psoralen plus ultraviolet A therapy," Photodermatology, Photoimmunology \& Photomedicine, vol. 11, no. 5-6, pp. 185-187, 1995.

[10] K. Danno, M. Tagikawa, and T. Horio, "The alterations of keratinocyte surface and basement membrane markers by treatment with 8-methoxypsoralen plus long-wave ultraviolet light," Journal of Investigative Dermatology, vol. 80, no. 3, pp. 172-174, 1983.

[11] T. Muramatsu, Y. Yamashina, T. Shirai, and T. Ohnishi, "UVB irradiation reduces the expression of pemphigoid antigens in organ-cultured normal human skin," Archives of Dermatological Research, vol. 286, no. 3-4, pp. 142-144, 1994. 


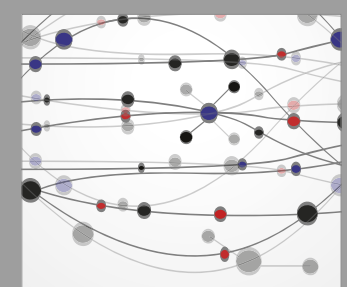

The Scientific World Journal
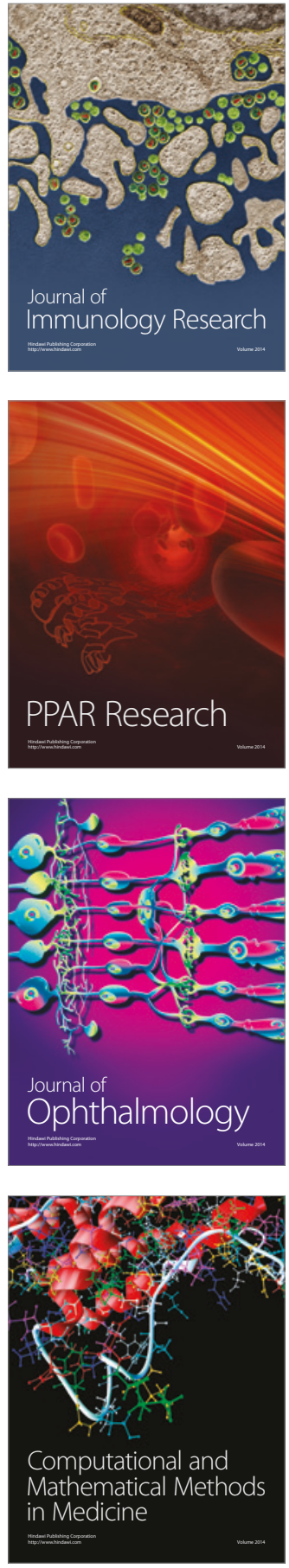

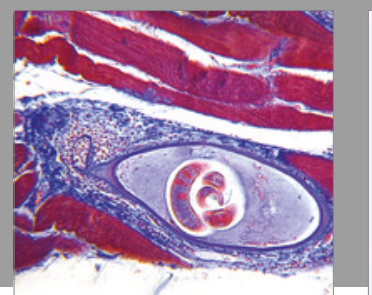

Gastroenterology Research and Practice
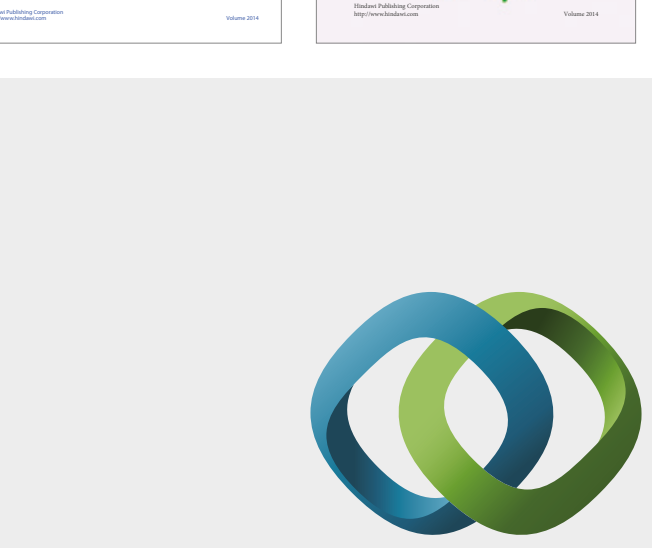

\section{Hindawi}

Submit your manuscripts at

https://www.hindawi.com
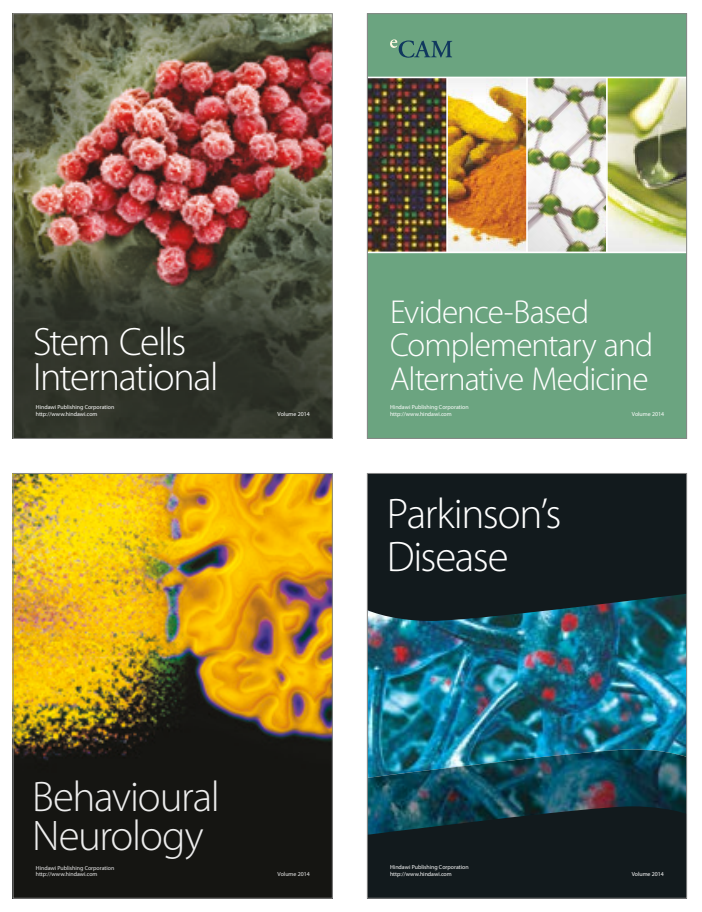
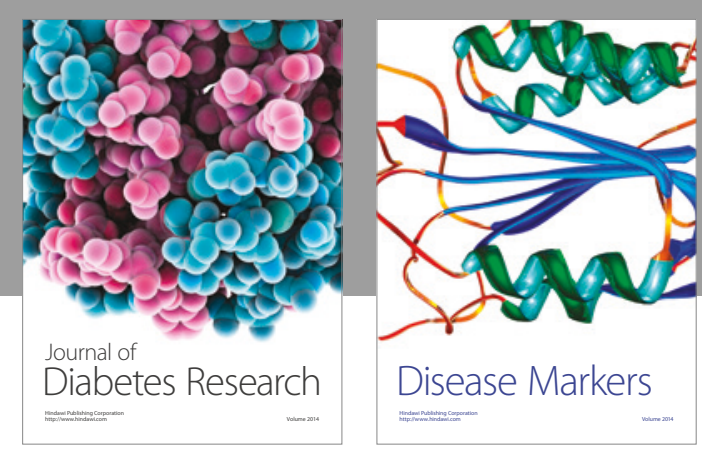

Disease Markers
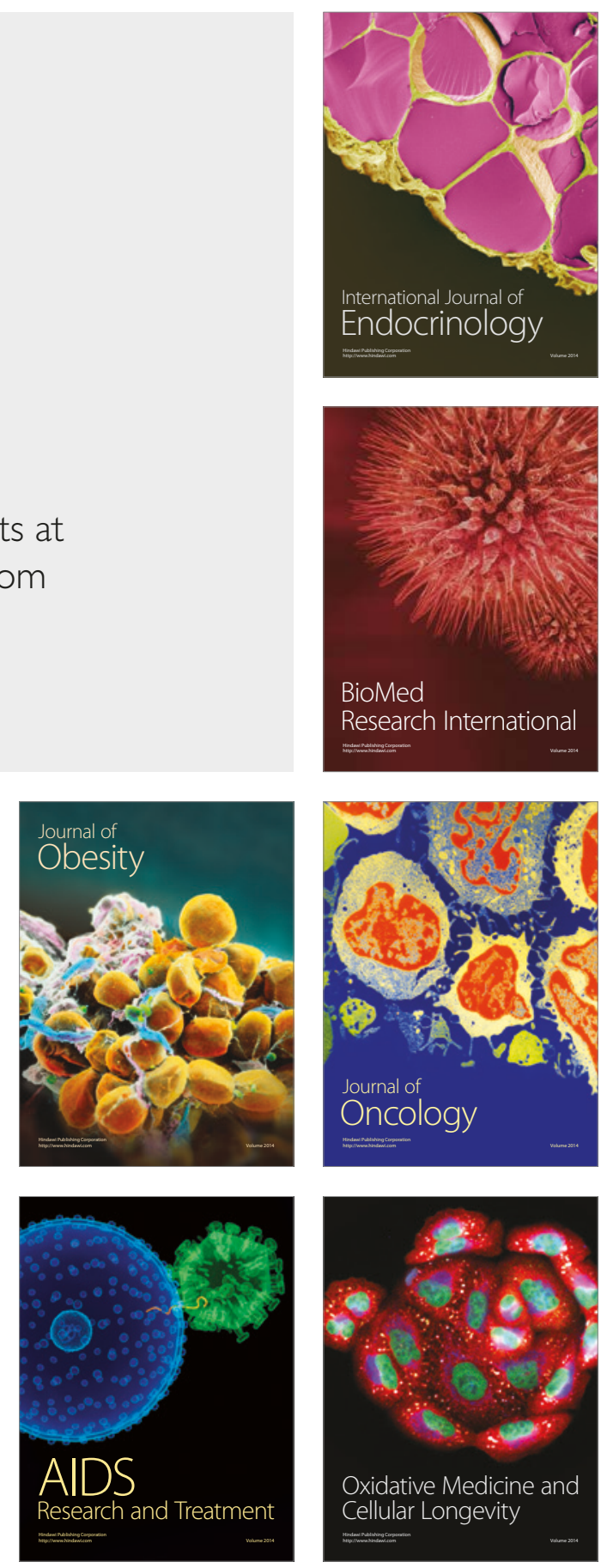